\title{
Manajemen Pengembangan Sarana Fasilitas Publik Kebun Bibit Wonorejo Surabaya untuk Meningkatkan Kepuasan Pengunjung
}

\author{
Yosef Richo, Siswo Martono dan Nur Luqman \\ Desain Produk, Fakultas Teknik Informatika, \\ Universitas Dinamika, Surabaya, Indonesia \\ e-mail: yosef@ stikom.edu
}

\begin{abstract}
Abstrak-Kebun Bibit Wonorejo Surabaya adalah salah satu taman dikota Surabaya yang mana keberadaannya bertujuan utama adalah untuk menumbuhkembangkan bermacam bibit-bibit tanaman yang nantinya bibit tersebut setelah dewasa dapat ditanam diarea perkotaan Surabaya, selain itu taman ini mempunyai berbagai peranan penting seperti sebagai sumber paru-paru kota, sarana rekreasi keluarga, hiburan, kesehatan, olahraga sampai pada berbagi ilmu dan budaya. Namun yang perlu diperhatikan adalah pada kebun bibit Wonorejo adalah sarana pendukung untuk fasilitas publik kurang diperhatikan dan kurang terawat seperti tempat dudukan dan tempat sampah dari aspek desain dan kenyamanannya sehingga image keindahan tempat serta kepuasan pengunjung dapat berkurang. Penelitian ini mencoba menyelaraskan proses manajemen rancang bangun desain produk sarana fasilitas publik Kebun bibit Wonorejo Surabaya sesuai dengan harapan pengunjung dan desainer. Untuk proses desain, konsep Total Product Design Conce (TPDC) digunakan peneliti untuk menentukan elemen dari desain: estetika, fungsionalitas dan maksud/tujuan yang nantinya dapat digunakan sebagai konsep desain. Pengukuran menggunakan kualitatif-kuantitatif dari pengunjung untuk mendapatkan data terkait kebutuhan perancangan, selanjutnya hasil olah data digunakan peneliti untuk merancang desain 2 dimensi hingga 3 dimensi dengan program komputer sehingga didapatkan hasil desain yang berwujud dan siap diproduksi nantinya
\end{abstract}

Kata kunci: manajemen, desain produk, dan fasilitas publik

Abstract-Surabaya Wonorejo Seed Garden is one of the parks in the city of Surabaya where its main purpose is to develop a variety of plant seeds that will later grow after the adults can be planted in urban areas of Surabaya, besides this park has various important roles such as the lungs of the city, facilities for family recreation, entertainment, health, sports and sharing knowledge and culture. But what needs to be considered is that in Wonorejo nursery is a support facility for public facilities that is less attention and less well maintained such as a place to sit and a trash can from the aspect of design and comfort so that the image of the beauty of the place and visitor satisfaction can be reduced. This study tries to harmonize the design management process of the design facilities for public facilities in Surabaya Wonorejo nursery in accordance with the expectations of visitors and designers. For the design process, the TPDC concept (Total Product Design Concept)concept is used by researchers to determine the elements of the design: Aesthetics, Functionality and Intentions that can later be used as Design concepts. Measurements using qualitativequantitative from visitors to get data related to design needs, then the results of data processing are used by researchers to design 2-dimensional designs to 3 dimensions with computer programs so that the design results are tangible and ready to be produced later.

\section{Keywords: management, industrial design, and public facilities.}

\section{PENDAHULUAN}

Taman kota merupakan kawasan yang penting bagi masyarakat, Hiruk pikuk kepadatan dan polusi udara serta aktivitas penduduk yang sibuk membuat peran dari taman sebagai tempat rekreasi kaluarga atau tempat melepas penat adalah cocok bagi masyarakat Surabaya dan taman adalah merupakan sarana fasilitas publik. Selain menjadi tempat rekreasi dan melepas kepenatan, taman kota juga mempunyai fungsi yang lain seperti: sebagai tempat bagi pengunjung untuk melakukan aktivitas-aktivitas positif, tempat melakukan interaksi sosial, tempat penghijauan atau paru-paru kota, tempat aksesbilitas berbagai fisik dan kegiatan, taman kota juga dilengkapi sarana-sarana penunjang yang lain seperti mushala, kantin, area olahraga, telepon umum, lokasi outbond, pendidikan, dan lain-lain [1].

Saat ini jumlah taman di Surabaya telah mencapai sekitar 54 buah, dengan memberikan tema yang sesuai dengan nama yang diberikan pada taman tersebut. Dari sekian banyak taman yang ada, taman yang baru dan perlu mendapat apresiasi menjadi tempat singgah warga kota Surabaya adalah Taman Kebun Bibit Wonorejo yang terletak di Jalan Wonorejo Surabaya. Rata-rata taman ini dikunjungi minimal 150 orang per hari, bukan hanya anakanak maupun remaja yang berkunjung ke sini, namun juga orang dewasa maupun orang tua. Puncak terjadinya 
keramaian di Taman Kebun Bibit Wonorejo adalah di akhir pekan, yaitu di hari minggu pagi.

Kebun Bibit Wonorejo memiliki berbagai keunggulan sebagai tempat wisata Murah dan Komplit ditengah kota Surabaya yang padat selain itu taman ini memiliki area yang cukup luas. Juga ada banyak spot menarik di Kebun bibit dengan luas sebesar 5,9 Hektare ini. Beberapa spot tersebut adalah: Danau, wall climbing, kandang rusa, kandang unggas, jogging track, playground, fitness area, taman bunga, terapi batu, rumah anggrek, bibit tanaman, rumah kompos, tempat berkemah, kran air siap minum, desain sarana publik, toilet, sentra wisata kuliner, dan lain-lain [2].

Tabel 1 menunjukkan macam fasilitas pada kebun bibit Wonorejo. Sedangkan Gambar 1 adalah tampilan keindahan lokasi kebun bibit Wonorejo Surabaya.

Tabel 1. Macam fasilitas public yang tersedia pada Kebun Bibit Wonorejo, Surabaya

\begin{tabular}{|l|l|l|l|}
\hline No & $\begin{array}{l}\text { Fasilitas Publik } \\
\text { kebun bibit } \\
\text { wonorejo }\end{array}$ & $\begin{array}{l}\text { Macam Produk } \\
\text { Penunjang }\end{array}$ & \multicolumn{1}{|c|}{$\begin{array}{c}\text { Fungsi bagi } \\
\text { pengunjung }\end{array}$} \\
\hline 1 & Tempat Parkir & Kanopi & $\begin{array}{l}\text { Untuk memarkir } \\
\text { kendaraan }\end{array}$ \\
\hline 2 & Area santai & $\begin{array}{l}\text { Tempat duduk, } \\
\text { tempat sampah }\end{array}$ & $\begin{array}{l}\text { Tempat berkumpul } \\
\text { antar pengunjung }\end{array}$ \\
\hline 3 & Gazebo & Gazebo & $\begin{array}{l}\text { Tempat berteduh dan } \\
\text { berkumpul }\end{array}$ \\
\hline 4 & Area bermain anak & $\begin{array}{l}\text { Tempat bermain, } \\
\text { tempat sampah, } \\
\text { dudukan }\end{array}$ & $\begin{array}{l}\text { Tempat bermain untuk } \\
\text { anak }\end{array}$ \\
\hline 5 & Jogging Track & $\begin{array}{l}\text { Bangku, lampu } \\
\text { jalan, jalan track }\end{array}$ & $\begin{array}{l}\text { Tempat untuk olah } \\
\text { raga jogging }\end{array}$ \\
\hline 6 & Kandang Unggas & Kandang & $\begin{array}{l}\text { Tempat memelihara } \\
\text { unggas }\end{array}$ \\
\hline 7 & Area taman bunga & $\begin{array}{l}\text { Bangku, pot } \\
\text { bunga, air minum } \\
\text { fasilitas publik }\end{array}$ & $\begin{array}{l}\text { Tempat show off } \\
\text { bunga dan memelihara } \\
\text { bunga }\end{array}$ \\
\hline 8 & Rumah Kompos & $\begin{array}{l}\text { Tempat } \\
\text { penyimpanan } \\
\text { sampah }\end{array}$ & $\begin{array}{l}\text { Tempat pengepul } \\
\text { sampah kompos }\end{array}$ \\
\hline 9 & Rumah Anggrek & $\begin{array}{l}\text { Bangku, tempat } \\
\text { penyimpanan } \\
\text { anggrek }\end{array}$ & $\begin{array}{l}\text { Tempat memelihara } \\
\text { anggrek }\end{array}$ \\
\hline 10 & Rumah berkemah & $\begin{array}{l}\text { Tempat pengepul } \\
\text { api unggun }\end{array}$ & $\begin{array}{l}\text { Area outbond bagi } \\
\text { pengunjung }\end{array}$ \\
\hline 11 & $\begin{array}{l}\text { Sentra wisata } \\
\text { kuliner }\end{array}$ & $\begin{array}{l}\text { Rombong } \\
\text { kuliner, dudukan, } \\
\text { tempat sampah }\end{array}$ & $\begin{array}{l}\text { Tempat kuliner bagi } \\
\text { pengunjung taman }\end{array}$ \\
\hline 12 & Wall Climbing & Wall climbing & Tempat berolah raga \\
\hline 13 & Terapi Batu & $\begin{array}{l}\text { Tracking batu, } \\
\text { dudukan, lampu }\end{array}$ & $\begin{array}{l}\text { Tempat refreshing } \\
\text { bagi pengunjung }\end{array}$ \\
\hline Spanau & Kandang Rusa & $\begin{array}{l}\text { Kran air siap } \\
\text { minum }\end{array}$ & $\begin{array}{l}\text { Kagi pengunjung } \\
\text { bagat ming mang gratis }\end{array}$ \\
\hline
\end{tabular}

\section{Produk Fasilitas Publik Kebun Bibit Wonorejo}

Didalam tiap area fasilitas kebun bibit, dilengkapi dengan fasilitas desain produknya untuk menunjang peran dari area tersebut, desain produk 'perabot' pada ini tentu tidak dapat dipisahkan dari fungsi area fasilitas publik, Desain Produk, peran desain produk pada area fasilitas publik selain sebagai penambah nilai fungsionalitas dari area fasilitas juga sebagai pemanis keindahan tempat tersebut yang selanjutnya dapat menambah tingkat kepuasan pengunjung yang mennajdi konsumennya [3], hal serupa yakni peran dari kualitas desain produk yang baik pada fasilitas public adalah sesuai dengan harapan konsumen dapat meningkatkan kepuasan dan loyalitas pengunjung [4] dan [5].

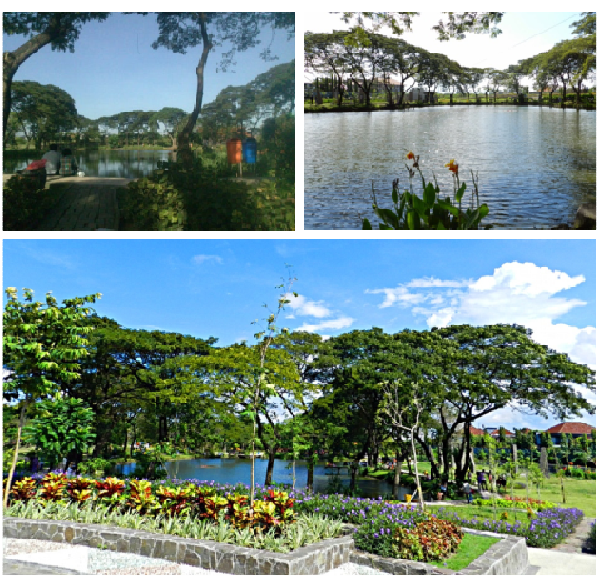

Gambar 1. Contoh penampakan lokasi Kebun Bibit Wonorejo.

Namun area fasilitas Kebun Bibit Wonorejo kurang didukung dengan kualitas fasilitas produknya, terdapat beberapa produk fasilitas publik yang ada yang sering digunakan pengunjung ditaman ini kurang memiliki konsep estetika dan pengerjaan desain yang baik sehingga kesan keindahan taman kurang dapat terapresiasi maksimal. Beberapa contoh produk fasilitas tersebut seperti tempat duduk, tempat bermain, jembatan, gazebo, sampah, rombong kuliner dan lain-lain (Gambar 2).
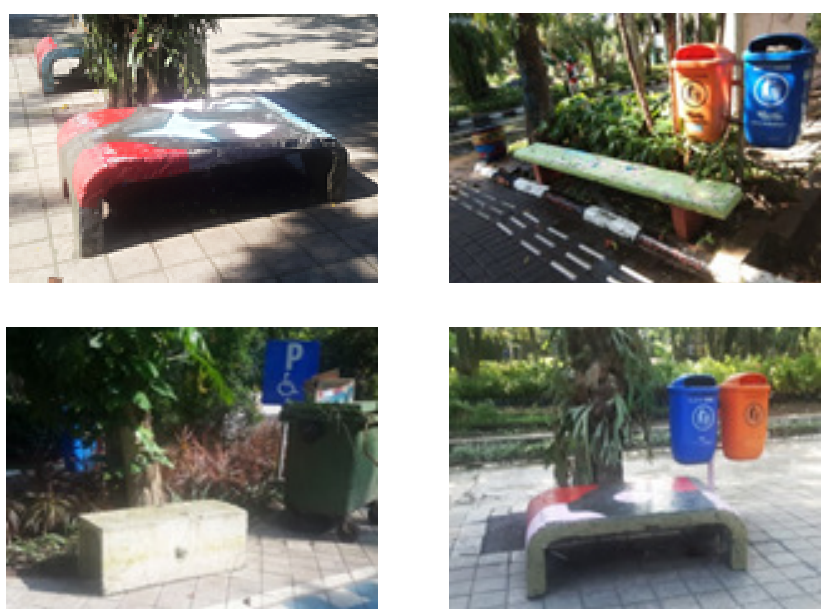

Gambar 2. Il;ustrasih desain produk fasilitas publik yang kurang mencerminkan keindahan Kebun Bibit Wonorejo.

Berdasarkan pengamatan dan tinjauan diatas, maka diperlukan penelitian untuk pengembangan desain produk fasilitas publik yang sesuai dengan harapan pengunjungnya serta dapat meningkatkan image Kebun Bibit Wonorejo Surabaya.

\section{Tujuan penelitian}

Penelitian ini bertujuan utama adalah untuk memperoleh desain produk fasilitas publik dari Kebun Bibit Wonorejo Surabaya berdasarkan sinergi harapan atau keinginan dari pengunjung (konsumen) dan desainer, sehingga diharapkan hasil desain nantinya dapat sesuai untuk mendukung kepuasan pengunjung berikutnya.

\section{Batasan penelitian}

Penelitian ini terbatas pada pengembangan desain produk untuk 1 area fasilitas publik pada Kebun Bibit Wonorejo. 


\section{Landasan teori}

\section{Kepuasan pengunjung}

Perlu dicermati kualitas terhadap produk fasilitas kebun bibit wonorejo dapat meningkatkan kepuasan dan loyalitas pengunjung yang menjadi konsumennya selanjutnya Loyalitas konsumen terhadap produk adalah berdasarkan efek dari pengalaman positif ketika telah mendapatkan kualitas fasilitas produknya, lebih lanjut adalah bahwa kepuasan pengunjung terhadap fasilitas public dapat terjadi ketika harapan dan kenyataan yang diinginkan pengunjung sesuai atau lebih (Gambar 3).

Untuk meningkatkan kepuasan dan loyalitas konsumen untuk kategori produk fasilitas public, maka fasilitas perlu memiliki nilai tambah pada konsumennya seperti: atraktif, kebersihan, layout atau desain yang menarik serta kenyamanan agar dapat meningkatkan kepuasan dan loyalitas pengunjung bahwa selain dari servis kepada konsumen peran dari kualitas fasilitas produk dapat mempengaruhi kepuasan konsumen [6].

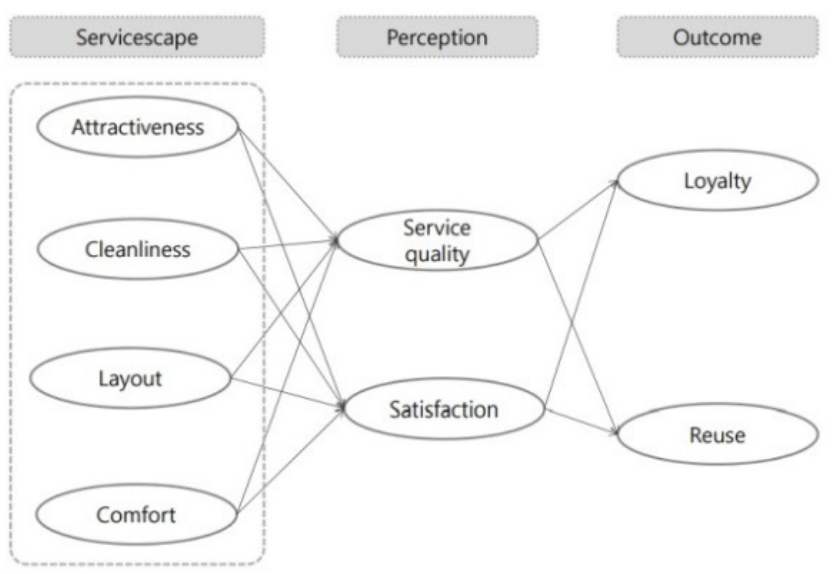

Gambar 3. Atribut elemen fasilitas publik menurut Lee dan Kim (2018).

\section{Total Product Design Concept (TPDC)}

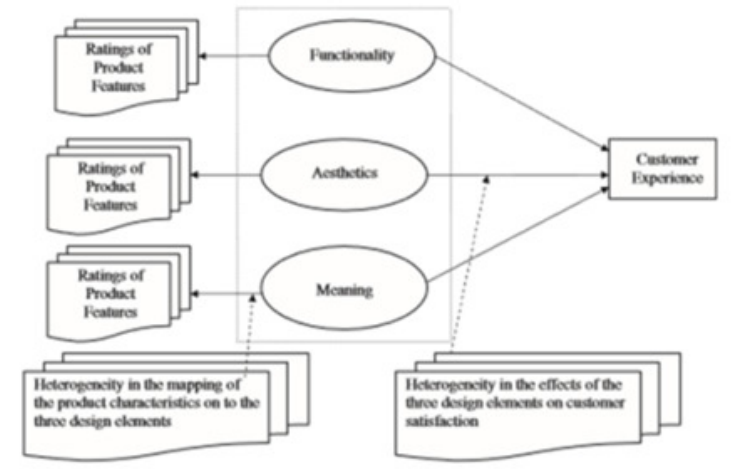

Gambar 4.Atribut elemen fasilitas publik menurut Lee dan Kim (2018)

Kualitas produk yang terkandung dalam kualitas servis kepada konsumen harus sesuai dengan karakter konsumennya. Jika suatu produk memenuhi harapan pelanggan, pelanggan akan senang dan mempertimbangkannya, kualitas dari produk. Terkait dalam perancangan desain suatu produk diperlukan adanya sinergi antar kebutuhan dari konsumen atau pengunjung dan kemampuan dari desainer yang menginterpertasikan maksud dari konsumen pada sebuah desain [7].

Metode perancangan berdasarkan TPDC (Total Product Design Concept) cocok digunakan bahwa dalam pembentukan desain yang sesuai dengan kriteria konsumen dan desainer, TPDC setidaknya mencakup 3 (tiga) aspek utama didalam desain produk (Fungsional, estetika dan maksud dari desain) agar konsumen merasakan kepuasan yang maksimal. Kemudian hasil TPDC dapat diolah menjadi sebuah nilai terukur pada alat ukur kuantitatif untuk kemudian dapat mudah digunakan desainer dalam menentukan arah desain produknya (Gambar 4).

Selanjutnya dari konsep diatas dapat diketahui bahwa atribut desain yang digunakan untuk penelitian pada desain adalah fungsional, estetika dan maksud/tujuan dari desain (Gambar 5).

\section{Proses Perancangan Desain}

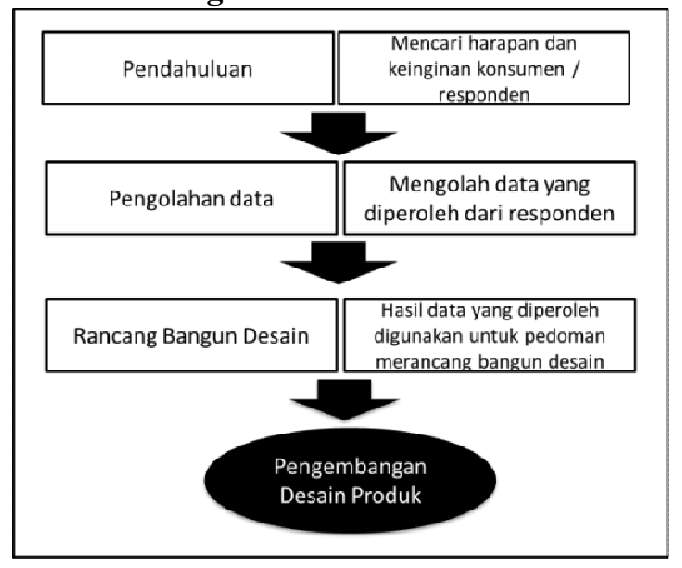

Gambar 5. Proses perancangan desain.

\section{a. Pendahuluan}

Pada tahap ini adalah dimulai dari bagaimana konsumen atau pengunjung kebun bibit Wonorejo menilai ekspektasi mereka terhadap area fasilitas publik beserta produknya hal ini dilakukan untuk melihat tingkat pemahaman peneliti akan persepsi dan harapan konsumen pada produk eksisting. Metode penilaian kepuasan pelanggan dipergunakan untuk menilai keinginan konsumen atas produk yang ada. Konsep kepuasan pelanggan dipergunakan untuk mengukur tingkat kepuasan konsumen dalam metode SERVQUAL. Mengacu kepada kesenjangan antara persepsi dan harapan konsumen terhadap produk yang ada menjadi landasan dalam mencari atribut produk yang akan menjadi dasar dalam proses pengembangan produk fasilitas publik [8].

\section{b. Pengolahan data}

Selanjutnya hasil kompilasi dari penilaian responden dikumpulkan dan dilakukan pengolahan data dengan menggunakan statistic, diharapkan hasil dari pengolahan data dapat memberikan area fasilitas kebun bibit wonorejo yang paling diharapkan untuk dilakukan sebuah perubahan beserta desain produknya, maka akan semakin tinggi kepuasan pelanggan yang dirasakan. Suatu produk hasil pengembangan nantinya dapat dikatakan sukses apabila mendapatkan respon positif dari konsumen yang diikuti dengan keinginan dan tindakan untuk membeli produk. 


\section{c. Rancangan produk}

Selanjutnya peneliti dilakukan eksekusi terhadap hasil dari pengolahan data kedalam rancangan desain produk dengan menggunakan program komputer untuk menghasilkan wujud desain berupa 2 dan 3 dimensi. Pada proses ini peran desainer menjadi utama untuk menentukan bentuk dari desain. Atribut desain yang digunakan desainer dalam menentukan arah desain dengan menggunakan metode TPDC dengan menggunakan 3 atribut untuk menentukan arah desain yakni: Fungsional, estetika dan maksud dari desain.

\section{METODE PENELITIAN}

Perancangan Desain yang digunakan adalah didasarkan dari pengembangan metode RDE (Rule Developing Experimentation) adalah metode penelitian yang digunakan untuk menghasilkan pengembangan produk dari sudut desainer yang didasarkan dari data respon kebutuhan konsumennya, dikarenakan desainer dianggap mampu meneruskan hasil komulatif data pada bentuk sebuah desain [9].

Proses perancangan yang dilakukan oleh desainer dalam menentukan bentuk produk berdasarkan elemen desain dari metode TPDC. Data yang diperoleh TPDC adalah didapatkan dari survei kuisioner kualitatif kepada responden pengguna fasilitas Kebun Bibit Wonorejo Surabaya. Selanjutnya Data diolah menjadi nilai kuantitaif agar diperoleh hasil yang terukur, dari sini peran dari penilaian pengunjung menjadi dasar dari proses perancangan produk Desainer, Survei kepada responden terkait dengan kebutuhan produk seperti:

a. Kesesuaian ekspektasi pengunjung terhadap produk fasilitas publik

b. Area fasilitas mana yang perlu dikembangkan

c. Produk fasilitas mana yang perlu dikembangkan

d. Kriteria TPDC mana yang dipilih responden untuk kebutuhan pengembangan desain fasilitas publiknya

e. Data pengunjung.

Survei berdasar kebutuhan konsumen untuk dasar perancangan desain adalah sesuai dengan Goftman dan Moskowitz alasan proses desain tersebut sesuai dengan penelitian ini dimana atribut TPDC yang terdiri dari Fungsional, Estetika dan Maksud dari desain menjadi tolok ukur bagi desainer.

Metode RDE yang digunakan desainer adalah dengan maksud mempermudah desainer dalam melakukan proses perancangan, dimana desainer menggunakan teknologi untuk rancang produk, teknologi dapat mempercepat eksekusi desainer dalam membuat alternative hingga final desain. Proses rancang produk desainer dengan RDE atau penggunaan Teknologi yang digunakan dalam penelitian ini adalah:

1. Desain 2D: Corel Draw dan Photoshop, dimana progam teknologi computer ini umum digunakan desainer untuk mendapatkan gambaran desain awal yang bersifat sketsa berwarna secara digital.

2. Desain 2D Terukur: Autocad, dimana program ini digunakan untuk mendapatkan gambaran desain secara terukur berupa gambar kerja yang nantinya ukuran ini dapat digunakan untuk proses produksi.
3. Desain 3D: 3DS Max dan Vray, program ini dapat mewujudkan visualisasi gambar 2D menjadi wujud solid $3 \mathrm{D}$ hingga terlihat seperti visual prototype, program ini berguna untuk mendapatkan gambaran utuh dari desain yang diharapkan oleh desainer.

Kuisioner diarahkan kepada pengguna atau pengunjung kebun bibit wonorejo dengan demikian hasil dari kuisinoer adalah tepat guna dan desainer yang menjadi perancang produk adalah berasal dari spesialisasi desain produk sesuai dengan kebutuhan penelitian.

\section{HASIL DAN PEMBAHASAN}

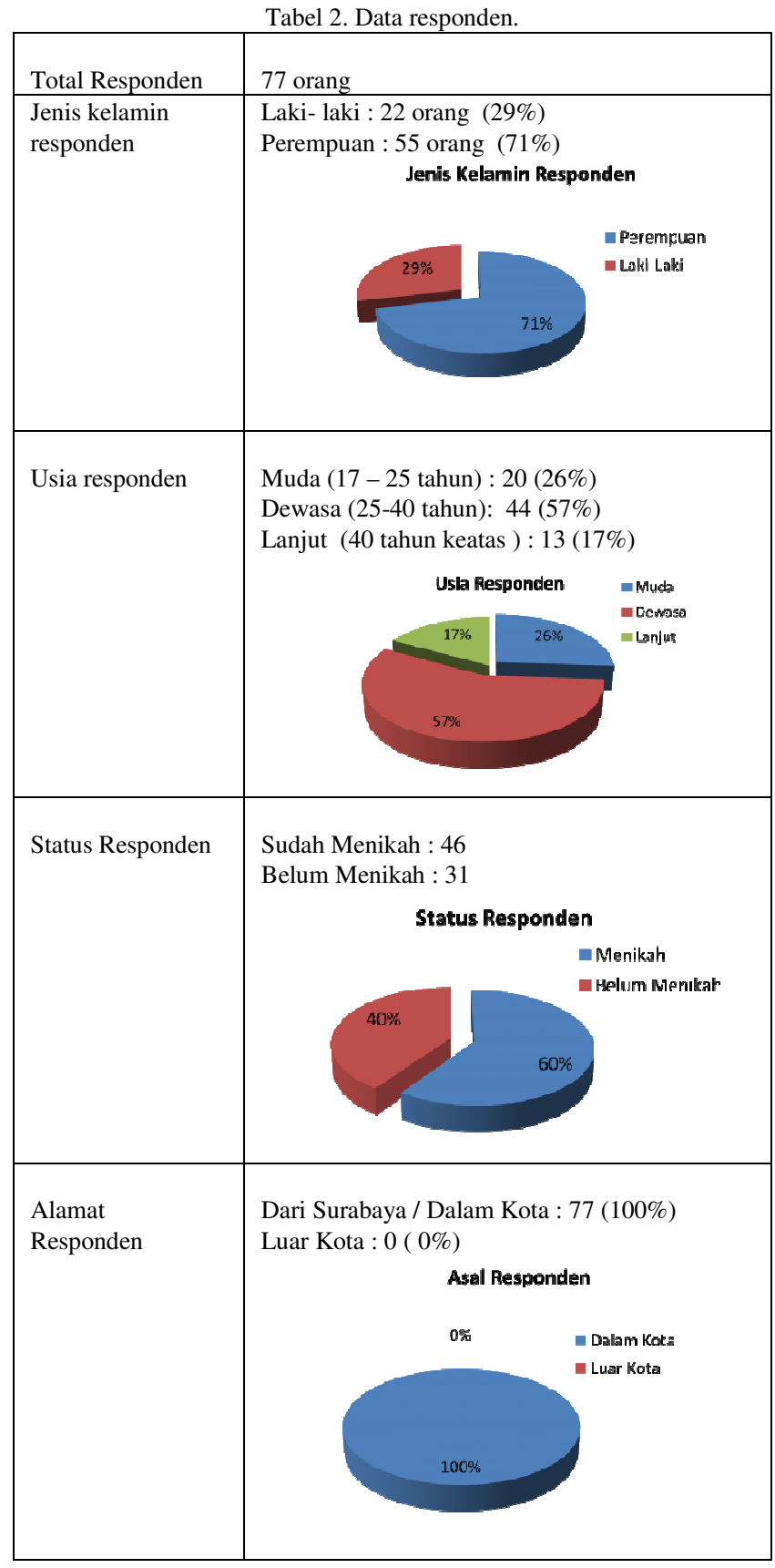

Setelah itu penelitian melakukan pengujian untuk memilih atribut dari elemen yang akan dipilih yang nantintya kepada responden, responden disini adalah pengunjung dari Kebun Bibit Wonorejo Surabaya dan telah atau pernah menggunakan produk fasilitas publik tempat tersebut. 
peneliti memberikan tahapan pertanyaan kualitatif kepada responden, responden yang akan dipilih adalah sebanyak 50 orang dengan asumsi statistic yang menyebutkan bahwa minimal uji kelayakan data adalah sebanyak 30 orang sebagai jarak kualitas dari tabulasi data. Responden. Survei yang dilakukan bertujuan untuk memilih elemen desain yang telah terpilih dari proses seleksi internal yang untuk kemudian hasil nya dapat dinilai secara kuantitatif dengan menggunakan skala likert sebagai pembanding, dan selanjutnya hasil dapat digunakan untuk menentukan arah perancangan desain dimana elemen desain yang terpilih disatukan pada desain baru sehingga membentuk new product development nantinya [10]. Selanjutnya dapat dilihat Tabel-tabel 2, 3 dan 4.

Dari hasil penilaian komulatif diatas didapat beberapa hal yakni:

1. Responden lebih banyak wanita dengan prosentase 71 persen.

2. Usia Responden rata-rata berusia muda dan dewasa.

3. Responden rata-rata terbagi antara sudah menikah dan belum

4. Responden seluruhnya berasal dari kota Surabaya atau dalam kota

5. Rata-rata pengunjung dapat dikatakan belum terlalu sering mengunjungi Kebun Bibit Wonorejo dengan kategori kurang sering kunjungan dengan prsentase beberapa bulan sekali $43 \%$ dan dengan kategori cukup sebulan sekali sebanyak $20 \%$

6. Kategori area fasilitas publik yang paling diinginkan responden untuk dibenahi adalah area santai kemudian area bermain anak

7. Sedangkan kesesuaian harapan fasilitas publik kebun bibit wonorejo dirasa kurang bagi responden, sebanyak $46 \%$ mengatakan kurang dan $35 \%$ menyebut cukup, untuk kategori puas atau sesuai dengan harapan hanya $19 \%$

8. Kriteria Desain yang diharapkan responden untuk produk fasilitas publik lebih mengarah bagaimana bentuk estetikanya yang bagus dan fungsinya dapat dimengerti pengunjung.

9. Bangku, tempat sampah dan tempat selfie Kebun Bibit Wonorejo yang banyak diharapkan responden agar dapat diperbaiki dari desainnya.

Tabel 3. Pengolahan data mengenai Kebun Bibit Wonorejo

\begin{tabular}{|c|c|}
\hline $\begin{array}{l}\text { Frekuensi mendatangi } \\
\text { kebun bibit }\end{array}$ & 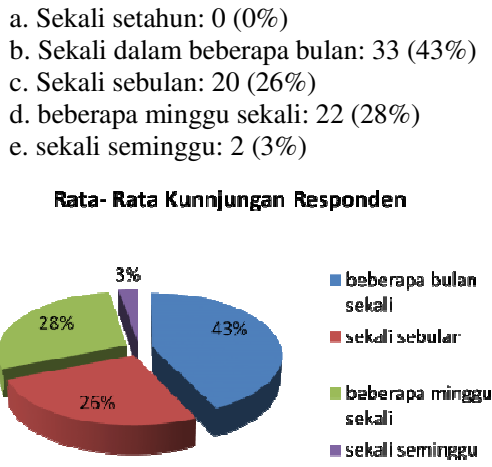 \\
\hline
\end{tabular}

Tabel 4. Pengolahan data mengenai Kebun Bibit Wonorejo (Lanjutan).

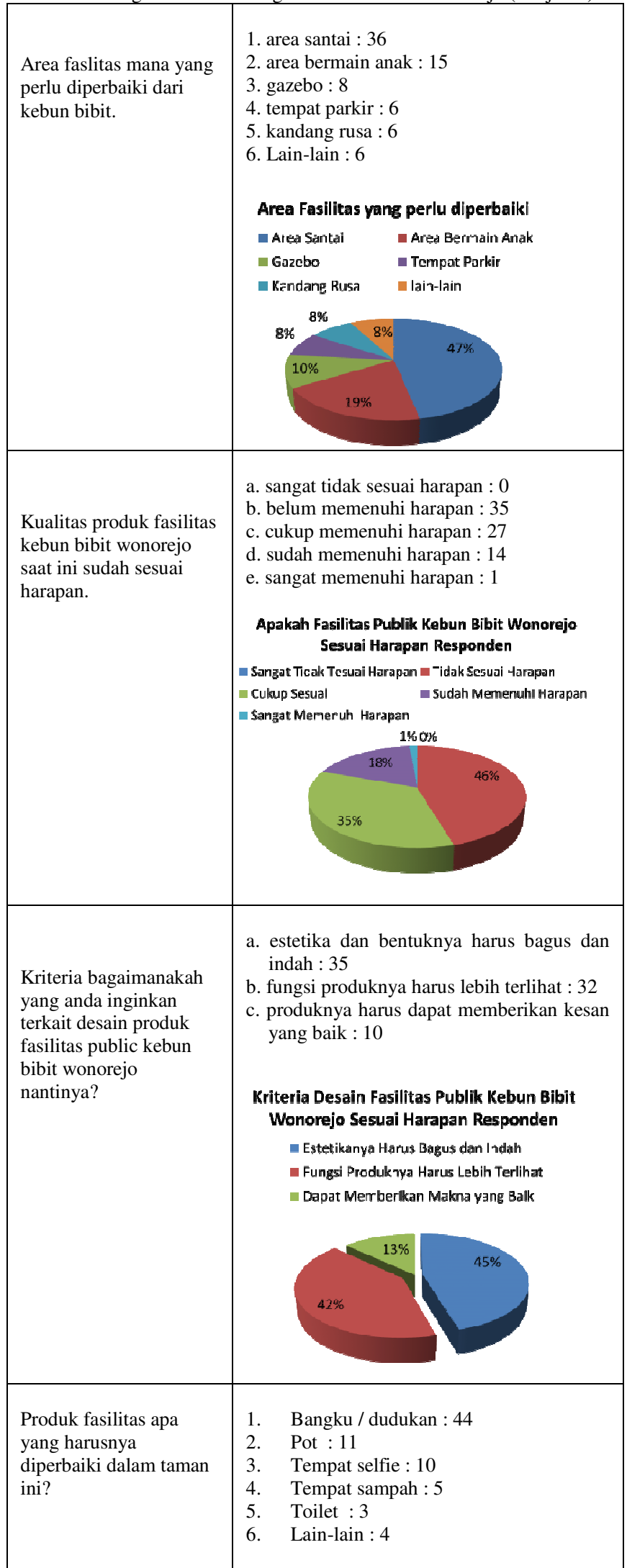

\section{Konsep desain}

Selanjutnya peneliti memilah berdasarkan tingkat kepentingan dan kebutuhan yang telah diperoleh sebelumnya dari data responden untuk diproses pada konsep desain. Peneliti dalam penelitian ini menggunakan hasil 
pilihan responden yang tertinggi yang dapat dijadikan dasar dari desain, berikut yang akan digunakan peneliti:

1. Produk yang Didesain adalah bangku pengunjung.

2. Aspek yang dipentingkan adalah desain yang harus estetis dan indah pada produk bangku.

3. Bangku pengunjung ini rencananya dapat ditempatkan pada area fasilitas santai Kebun Bibit Wonorejo Surabaya.

4. Bangku ini cocok digunakan untuk pengunjung berusia muda maupun dewasa.

5. Bangku ini dapat digunakan oleh pengunjung yang sudah menikah atau berkeluarga bersama-sama.

6. Bangku ini dapat mencitrakan kesan Surabaya dan kebun bibit sesuai dengan pengunjung dari kota Surabaya.

7. Pengunjung perempuan dapat menyukai dalam menggunakan desain bangku nantinya.

8. Desain bangku nantinya diharapkan dapat meningkatkan ekspektasi atau nilai kepuasan pengunjung.

\section{Uji desain dengan bantuan teknologi (RDE)}

Setelah konsep desain terpilih, selanjutnya peneliti bertindak sebagai desainer mencoba mengaplikasikan kedalam sebuah bentukan desain, desain didapatkan dari hasil konsep desain dana arah desain menggunakan metode TPDC dimana hasil desain nantinya dapat memuat unsur fungsional, estetika dan maksud dari desain. Desainer memerlukan beberapa proses untuk menindaklanjuti konsep tersebut menjadi final desain.

Tabel 6: Proses Desain Dengan RDE

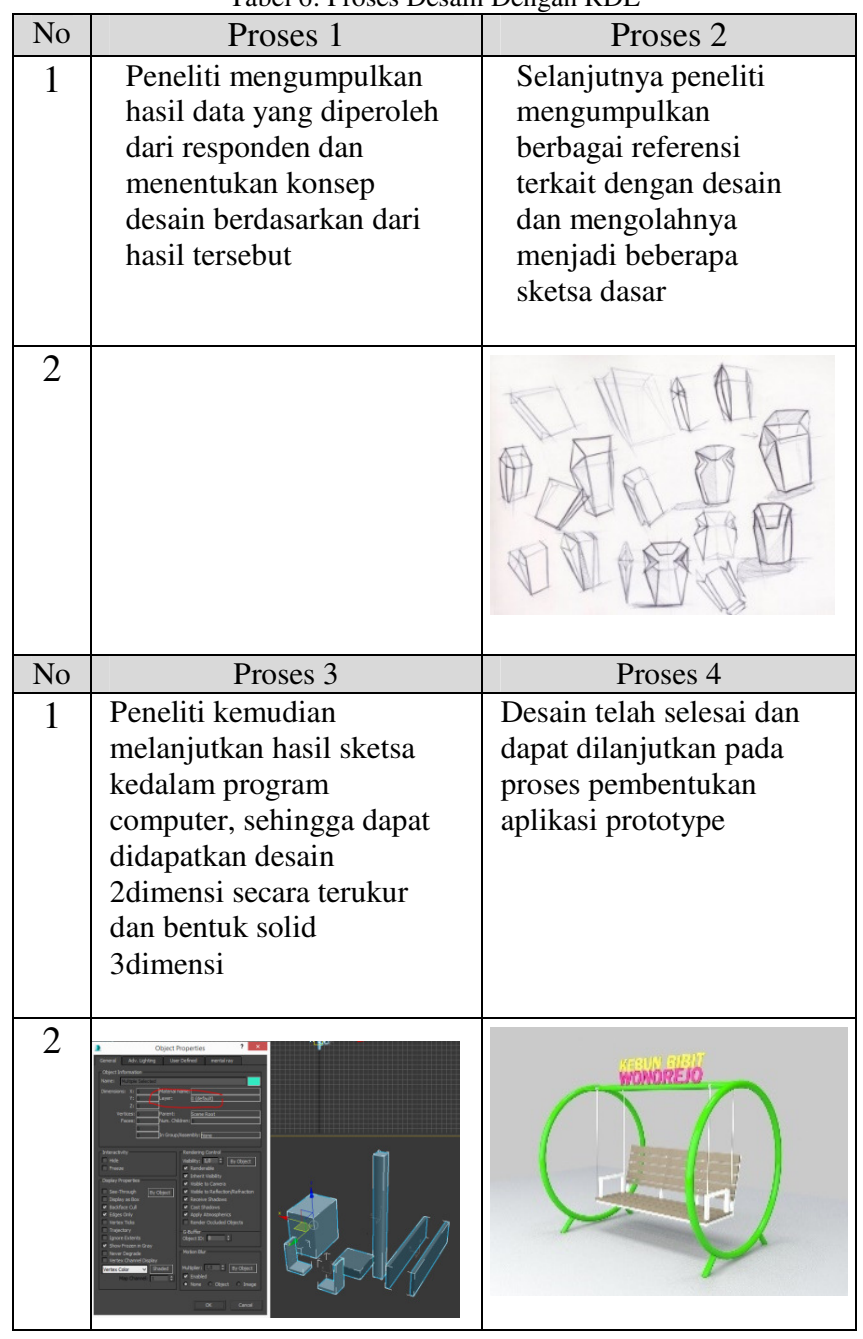

\section{Desain 2D}

Hasil desain 2D adalah hasil rancangan dari proses menggunakan teknologi, gambar 2D diatas digunakan desainer untuk mengetahui ukuran dan gambar proporsional (gambar kerja) yang nantinya dapat dilanjutkan pada bentukan 3D, pada gambar diatas dapat ditunjukan tampilan desain bangku taman dari sudut depan dan samping secara terukur dan proporsional (Gambar 6).

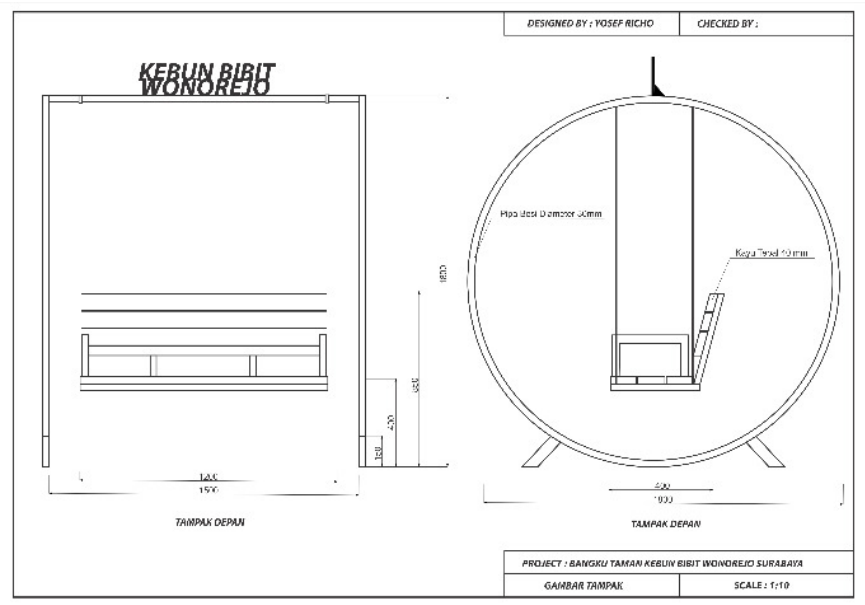

Gambar 6. Rancangan desain 2D.

\section{Desain 3D}

Selanjutnya desainer melanjutkan proses hasil desain 2D tersebut dengan menggunakan program 3DSmax dan rendering Vray untuk memperoleh hasil visual bangku taman secara solid atau 3D, warna dan pencahayaan serta material diberikan pada olah gambar agar tampak realistis dan menyerupai prototype yang diinginkan (Gambar 7).
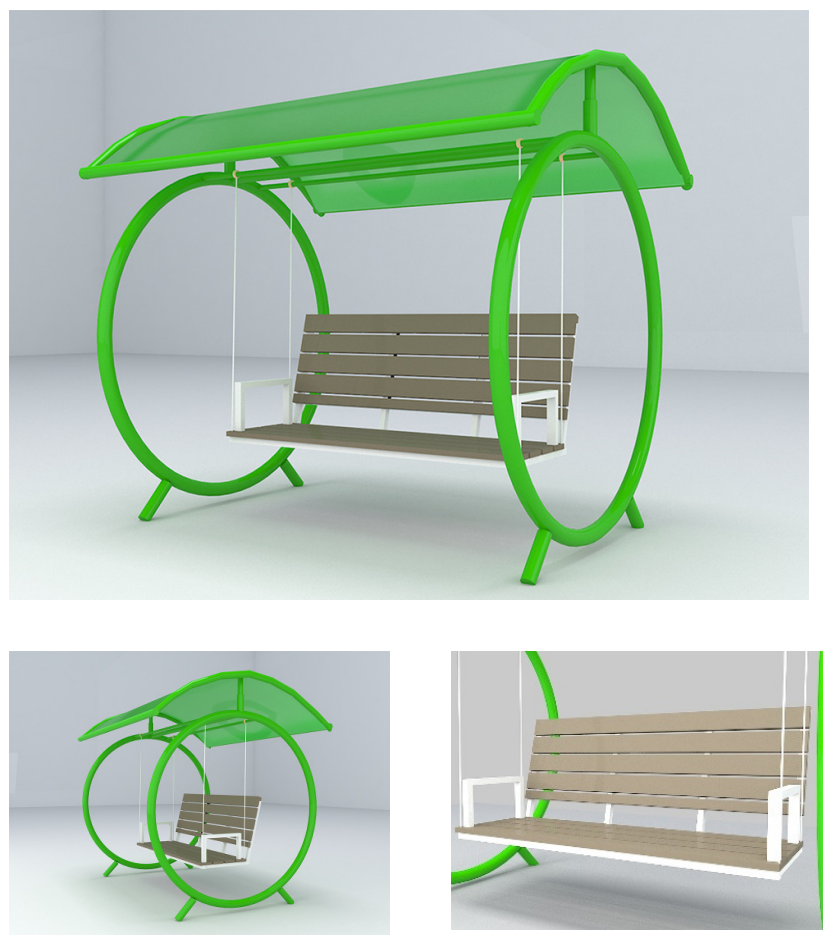

Gambar 7. Hasil 3D Modeling Berdasar RDE.

Hasil prototipe

Prototipe bangku taman dapat dilihat pada Gambar 8 . 

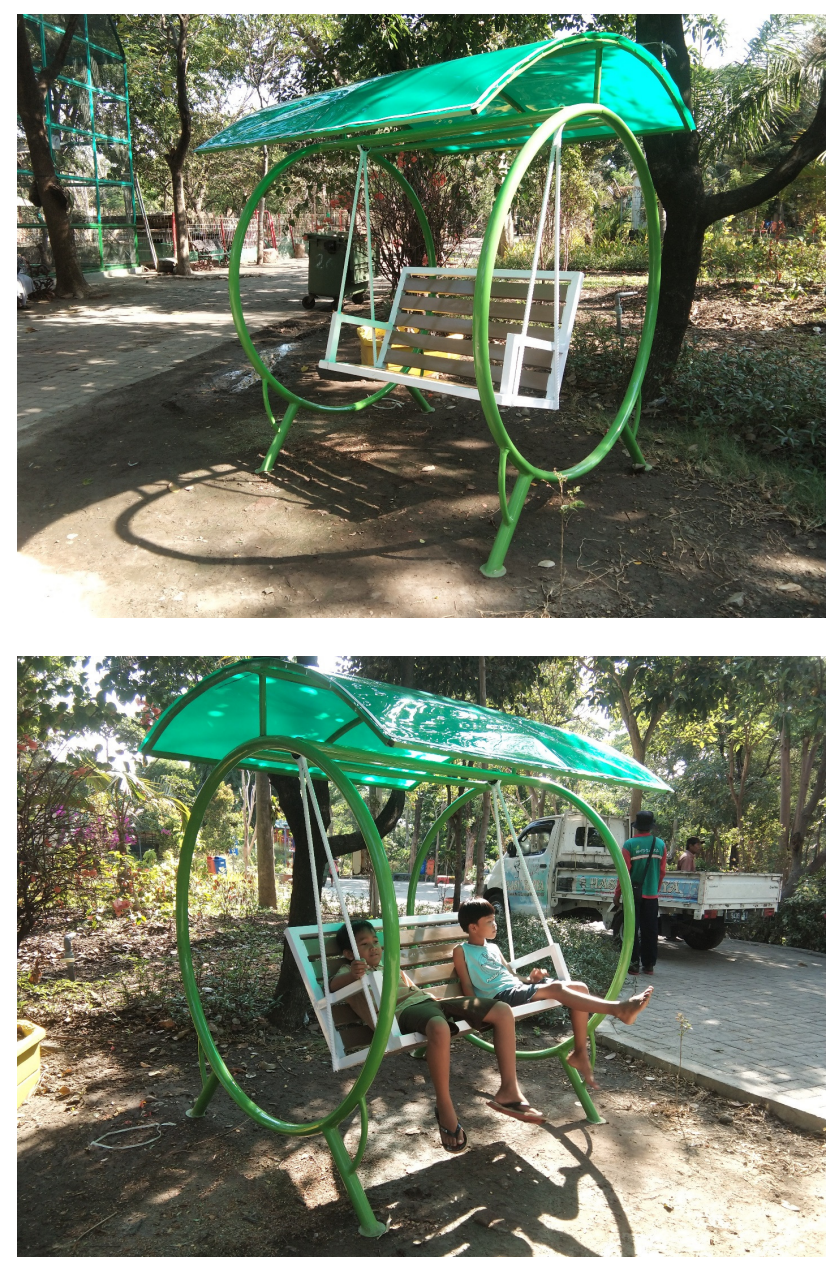

Gambar 8. Hasil prototipe desain.

\section{KESIMPULAN}

Desain bangku yang sudah dapat diwujudkan adalah hasil implementasi dari sinergi antara peran desainer sebagai pengelola input data dari responden menjadi bentuk visual. Pada desain terebut dapat menunjukan bagaimana peran unsur dari TPDC dalam membentuk karakter desain:

a. Fungsional : dalam aspek fungsional, desainer tidak merubah fungsi utama produk yakni sebagai bangku taman, namun desainer menambahkan beberapa point tambahan lain didalam desain yakni bangku yang dapat menjadi ayunan serta penanda nama Kebun Bibit Wonorejo

b. Estetika : Desainer memberikan unsur estetika pada bentik rangka bangku yang bulat agar terlihat menarik dan unik, namun tidak merubah fungsi utama dari produk

c. Makna dari Desain : warna hijau pada rangka bangku menunjunjukkan makna khas kota surabaya sekaligus makna hijau dari Kebun Bibit Wonorejo.

Hasil desain berdasarkan kebutuhan responden adalah sebagai berikut:

1. Produk ini adalah redesain dari bangku Kebun Bibit Wonorejo yang lebih segar sesuai dengan rekomendasi responden yang menginginkan pembaruan pada desain bangku.
2. Aspek estetika adalah yang terutama pada desain sesuai dengan kebutuhan responden agar bangku memiliki estetika yang lebih menarik dari sebelumnya, maka desainer melakukan renovasi pada desain yang berbentuk lingkaran dan warna yang menarik serta adanya tambahan berupa ayunan.

3. Desain Bangku ini dapat diletakkan pada area santai yang rindang Kebun Bibit Wonorejo dan material yang kuuat dari pipa besi diharapkan tahan cuaca dan benturan untuk area outdoor.

4. Desain Bangku ini dapat dinaiki secara perorangan maupun berpasangan, karena kebutuhan responden adalah mayoritas sudah menikah.

5. Warna yang cerah pada desain adalah agar dapat mudah dikenali dan menarik bagi pengunjung usia muda dan dewasa sesuai mayoritas responden yang berusia muda dan dewasa.

6. Kesan citra Surabaya dan Kebun Bibit Wonorejo yang rindang dapat teraplikasikan pada desain yang berwarna hijau.

7. Desain menghindari sudut-sudut tajam diharapkan dapat disukai pengunjung wanita dimana mayoritas responden adalah wanita

8. Diharapkan dengan adanya desain yang menarik dan tambahan fitur ayunan pada bangku dapat disukai oleh pengunjung nantinya dan meningkatkan ekspektasi terhadap kepuasan berkunjung pada Kebun Bibit Wonorejo Surabaya.

\section{Penelitian selanjutnya}

Penelitian ini bertujuan utama adalah untuk mendapat desain yang diinginkan dari pengunjung Kebun Bibit Wonorejo Surabaya melalui responden penelitian selain itu desain itu mencoba membantu kinerja dari desainer yang bersifat visual dan kreatif melalui hasil pengolahan data dari responden yang bersifat eksakta atau berupa angka. Dalam penelitian ini menunjukan hasil dari eksakta dapat diolah desainer menjadi bentuk visual dan new product development, peran dari metode TPDC juga dapat mempermudah arah desainer dalam menemukan karakter visual yang diperlukan dan desain menggunakan proses teknologi (RDE) juga dapat mempercepat proses kerja desainer.

Penelitian ini memiliki keterbatasan waktu yakni pengukuran kembali hasil desain yang sudah diolah desainer di nilai kempali kepada responden berikutnya, apakah hasil desain yang baru tersebut dapat meningkatkan ekspektasi atau kepuasan pengunjung dari produk sebelumnya dan juga penelitian ini juga terbatas pada ruang lingkup area Kebun Bibit Wonorejo dimana responden yang diukur dari pengunjung yang datang ke area lokasi pada beberapa waktu tertentu saja, selain itu kesulitan peneliti untuk memberikan pemahaman kepada respodenuntuk mengisi angket dikarenakan responden banyak dari dari kalangan menengah bawah dan tingkat akademisi yang kurang sehingga dibantu oleh peneliti dalam mengisi.

Saran dalam penelitian selanjutnya adalah bagaimana peneliti selanjutnya dapat lebih mudah memberikan pemahaman kepada berbagai lapisan masyarakat dalam mengisi kuisioner serta menggunakan berbagai metode yang lebih terkini untuk memandu desainer agar dapat bergerak menentukan arah desainnnya. 


\section{DAFTAR PUSTAKA}

[1] Rosita Endang Kusmaryani, Fungsi Psikilogis Taman Kota, "Buletin Jurnal UGM", Vol 9 No 2 (2001)

[2] http://kabarsurabaya.org/kebun-bibit-wonorejo-lokasiwisata-murah-dan-komplit/

[3] Wisnuprasetya, "Estetika Pada Desain Bangku Taman Untuk Anak Di Kota Surabaya". Seminar Nasional Sains dan Teknologi Terapan III 2015 Institut Teknologi Adhi Tama Surabaya ISBN 978-602-985691-0 (2015)

[4] Lee and Kim, Effects of Servicescape on Perceived Service Quality, Satisfaction and Behavioral Outcomes in Public Service Facilities. "Journal of Asian Architecture and Building Engineering" ISSN: 13467581 (Print) 1347-2852 (Online) Journal homepage: https://www.tandfonline.com/loi/tabe20 (2018)

[5] Hoe dan Mansori, The Effects of Product Quality on Customer Satisfaction and Loyalty: Evidence from Malaysian Engineering Industry, "International Journal of Industrial Marketing", 2018, Vol. 3, No. 1, ISSN 2162-3066
[6] Jahanshahi and Gashti, Study the Effects of Customer Service and Product Quality on Customer Satisfaction and Loyalty, "International Journal of Humanities and Social Science" Vol. 1 No. 7; [Special Issue -June 2011]

[7] Banahene dan Asamoah, Analysis of SERVQUAL Application to Service Quality Measurement and Its Impact on Loyalty in Ghanaian Private Universities. "Journal of Management and Strategy", Vol. 8, No. 4 (2017)

[8] Leonnard The Performance of SERVQUAL to Measure Service Quality in Private University, "Journal on Efficiency and Responsibility in Education and Science", Vol. 11, No. 1, pp. 16-21, online ISSN 1803-1617, printed ISSN 2336-2375, doi: 10.7160/ eriesj.2018.110103 (2018)

[9] Alex Goftman dan Howard R. Moskowitz. Accelerating Structured Consumer-Driven Package Design," Journal of Consumer Marketing" p 157-168 (2010)

[10] Hair, Black, and Babin, "Multivariet Data Analysis". Book statistic Seventh Edition (2009) 